\title{
Evaluation of sugarcane introgression lines for resistance to brown rust disease caused by Puccinia melanocephala
}

\author{
Xiao-Yan Wang, Wen-Feng Li, Ying-Kun Huang, Xin Lu, Zhi-Ming Luo, Jiong Yin, Hong-Li Shan \& \\ Rong-Yue Zhang
}

Sugarcane Research Institute, Yunnan Academy of Agricultural Sciences, Yunnan Key Laboratory of Sugarcane Genetic Improvement, Kaiyuan 661600, Yunnan, China

Author for correspondence: Yingkun Huang, e-mail: huangyk64@163.com

\begin{abstract}
Sugarcane brown rust disease caused by Puccinia melanocephala is one of the important fungal diseases affecting sugarcane yield around the world. Cultivar resistance is the most appropriate control method for this disease. In this study, 62 introgression lines chosen from the crossing Saccharum officinarum L. cv. Ludashi x Erianthus rockii Yunnan 95-19 were evaluated for brown rust resistance using artificial inoculation. More than 30\% of the introgression lines were identified as resistant. Clones Yunye 09-609, Yunye 09-618, Yunye 09-622, Yunye 09-636, Yunye 09-637, Yunye 09-645, Yunye 09-647 and Yunye 09-652 were shown to have high levels of resistance. The resistant lines identified in this study could be used as sources of brown rust resistance in sugarcane breeding programs.
\end{abstract}

Key words: Erianthus rockii, Puccinia melanocephala, Saccharum officinarum, breeding.

\section{INTRODUCTION}

Sugarcane is an important sugar crop grown in China. Yunnan Province has the second largest area planted in China and produces approximately 1,775,000 tons of crystal sugar annually. Sugarcane is mostly grown by resource-poor farmers who generate income from the sale of sugarcane. It is also an increasingly important energy material and can promote sustainable development (Cai \& $\mathrm{Wu}, 2006)$.

Sugarcane brown rust (SCBR) is caused by Puccinia melanocephala H. Syd. \& P. Syd. Disease symptoms initially include yellowish spots on both leaf surfaces; subsequent flecks become reddish brown with sporulating pustules developing on the lower leaf surface of susceptible cultivars. The disease has a wide distribution and occurs in almost all sugarcane-growing countries (Ryan, 1989), including China. SCBR was first recorded in Yunnan Province in 1982. Previously, the disease had only been reported in some areas of Changning and Gengma in Yunnan Province. With increased planting areas, frequent introduction of new seed canes, single variety plantings and a conducive climate, the disease quickly spread throughout southwest of Yunnan Province (Huang \& Li, 2002). In severe cases, yield and sucrose content reductions of $40 \%$ and $30 \%$ were recorded in highly susceptible cultivars (Huang \& Li, 1998). High yield losses have been reported in other areas of the world (Comstock et al., 1992a; Comstock et al., 1992b; Comstock \& Raid, 1994) and SCBR has been responsible for the withdrawal of commercial cultivars in many sugarcane growing countries. Yield losses of 50\% were estimated in Mexico in 1981-1983 in the susceptible cultivar B 4362 (Comstock et al., 1992c). The requirement for frequent fungicide applications and the resulting low net profit generally precludes this management strategy for controlling SCBR (Jiang, 1985), making cultivar resistance the most viable alternative.

Although sugarcane breeding is complicated by the complex sugarcane genome (high level of ploidy, aneuploidy, and interspecific hybrid origin), progress in breeding for SCBR resistance has been rapid, as this trait is reported to have both narrow and broad-sense heritability (Comstock et al., 1992c). Modern sugarcane varieties are derived from a relatively few interspecific hybrids between Saccharum officinarum L. and S. spontaneum L., resulting in a narrow germplasm base (Berding \& Roach, 1987). To increase this restricted genetic base breeders have been interested in the introgression of genes from wild species, including Erianthus rockii Keng.

Erianthus rockii is a precious wild relative of Saccharum that grows at areas with altitude of 500-2700 $\mathrm{m}$ in Sichuan, Yunnan and the Tibet regions of China. This specie is of interest to sugarcane breeders in China since it is vigorous, drought and cold tolerant, has good ratooning ability and SCBR resistance ( $\mathrm{Li}$ et al., 2005; Liu et al., 2009). It is currently being used in sugarcane introgression programs at the Yunnan Sugar Research Institute (YSRI). Inter-generic crosses between $S$. officinarum cv. Ludashi and E. rockii cv. Yunnan 95-19 have been made to widen the hybrid germplasm base. These hybrids may be useful for incorporating new traits such as drought, cold and disease tolerance into commercial sugarcane cultivars. The 
objective of this study was to evaluate the SCBR resistance of some innovative introgression lines.

\section{MATERIALS AND METHODS}

\section{Experimental site}

This study was conducted under greenhouse conditions at YSRI, Yunnan Academy of Agricultural Science, Yunnan, China. The planting materials were obtained from the National Nursery of Sugarcane Germplasm Resources (NNSGR) of YSRI.

\section{Preparation of spore suspension}

One day before experimental inoculation, urediospores of $P$. melanocephala were collected from infected plants growing in Pingbian, Yunnan province. Spore suspensions were prepared by flooding leaves with sterile distilled water and dislodging the spores with a small brush. The spore concentration was quantified and standardized to $5 \times 10^{4}$ spores $\mathrm{mL}^{-1}$ with a hemocytometer.

\section{Screening for resistance to $P$. melanocephala}

Sixty two clones were selected from the germplasm introgression program at YSRI; parents were also evaluated at the same time. Mintang 70-611 was chosen as the resistant cultivar, while Xuan 3, Guitang 89-5, M105, Guitang 84332 and P44 were used as susceptible check cultivars ( $\mathrm{Li}$ et al., 2008).

Planting was carried out in August of 2010. For getting the healthy seedling, stalks were cut into singlebuds, soaked in cold, running water for $48 \mathrm{~h}$ and then treated at $50 \pm 0.5^{\circ} \mathrm{C}$ for 2 hours. Subsequently, the buds were submerged in a mixture of Dichlorvos $80 \%$ EC and Carbendazim 50\% WP for 5 to $10 \mathrm{~min}$. Thereafter, buds were planted in plastic pots $(35 \mathrm{~cm}$ diameter, $30 \mathrm{~cm}$ depth) filled with a steam sterilized mixture of soil and organic matter $(3: 1 \mathrm{v} / \mathrm{v})$ and $60 \mathrm{~g}$ compound sugarcane fertilizer $(\mathrm{N}: \mathrm{P}: \mathrm{K}=10: 10: 5)$. The plants were re-fertilized with the same fertilizer every two months. Each clone was replicated three times.

At two months after planting, all lines and controls were inoculated with spore suspensions using a handpressured sprayer until saturation of the leaf surface. Relative humidity was maintained by irrigation 2-3 times every day to ensure high humidity for spore germination. Ratings were undertaken when brown rust symptoms became obvious in the susceptible cultivars (approximately 4-5 weeks after inoculation). Disease reactions were rated on a 1 to 9 scale, this scale is based on visual assessment of the disease symptoms: 1 = no symptoms; 2 = yellow flecks; $3=$ few pustules; $4=$ some pustules, moderate number of pustules of lower leaves; 5 = moderate number of pustules, slight premature necrosis of lower leaves; $6=$ numerous pustules, more premature necrosis of lower leaves than $5 ; 7$ $=$ numerous pustules, death of lower leaves; $8=$ numerous pustules, death of upper leaves; and $9=$ numerous pustules, extensive leaf necrosis. Rust ratings of 1 was considered highly resistant; 2, resistant; 3, moderately resistant; 4, moderately susceptible; 5 to 7 , susceptible; 8 to 9 , highly susceptible (Comstock et al., 1992b). An average of the three ratings is reported.

\section{RESULTS}

Out of 62 clones screened for brown rust resistance, 25 showed a disease reaction rating lower than 3 . Of these 25 , seven were moderately resistant, 10 resistant and eight were rated highly resistant. About $13 \%$ of total introgression lines investigated showed high levels of resistance to SCBR (Table 1). Out of 62 introgression lines, one was moderately susceptible, 28 were susceptible, and eight were high susceptible (Table 1). The female parent $S$. officinarum $\mathrm{L}$. cv. Ludashi showed resistance reaction, while E. rockii. cv. Yunnan 95-19 (used as male parent) was highly resistant; the SCBR-resistant cultivar Mintang 70-611 also showed a highly resistant reaction. All susceptible cultivars had sporulating pustules after four weeks and showed highly susceptible reaction.

\section{DISCUSSION}

The finding of highly resistant sugarcane introgression lines in this study is promising for the potential incorporation of new genes for resistance to SCBR into commercial varieties. However, whether the resistance found in the tested clones originates from genes not yet present in commercial varieties remains to be seen. This will require molecular studies to elucidate. The clones found to be resistant are being further tested in advance yield trials, in different agri-ecological zones for broad spectrum SCBR resistance, in conjunction with other important agronomic traits.

The artificial inoculation technique described in this paper provides an alternative ( $\mathrm{Li}, 1980$; Taylor, 1992) reliable, rapid and simple approach for evaluating a large population of sugarcane clones for resistance to SCBR; this may enhance breeding efficiency.

From the results obtained in this work, it appears that the female parent (S. officinarum L. cv. Ludashi) and the male parent (E. rockii. cv. Yunnan 95-19) were both resistant to SCBR, $40.3 \%$ of their progeny also were resistant. The level of susceptibility resulting from a resistant vs. resistant cross is different from the results reported by Ramdoyal et al. (2000), who found that $70-80 \%$ of progenies from such a cross were resistant.

Results on the inheritance of SCBR resistance are not conclusive. Tai et al. (1981) observed marked transgressive segregation towards susceptibility in bi-parental crosses and selfed families and suggested that rust resistance was partially dominant. Intermediate heritabilities for rust resistance were reported by Tai et al. (1981) and Gonzalez et al. (1987), whereas high narrow-sense and broad-sense 
Evaluation of sugarcane introgression lines for resistance to brown rust disease...

TABLE 1 - Disease reaction and brown rust (Puccinia melanocephala) ratings of sugarcane Erianthus rokii introgression lines after artificial inoculation

\begin{tabular}{|c|c|c|}
\hline Germplasm & Disease rating & Reaction $^{\mathbf{a}}$ \\
\hline Yunye09-601 & 7 & S \\
\hline Yunye09-602 & 7 & $\mathrm{~S}$ \\
\hline Yunye09-603 & 8 & HS \\
\hline Yunye 09-604 & 2 & $\mathrm{R}$ \\
\hline Yunye 09-605 & 2 & $\mathrm{R}$ \\
\hline Yunye 09-606 & 2 & $\mathrm{R}$ \\
\hline Yunye 09-607 & 2 & $\mathrm{R}$ \\
\hline Yunye 09-608 & 3 & MR \\
\hline Yunye 09-609 & 1 & HR \\
\hline Yunye 09-610 & 6 & $\mathrm{~S}$ \\
\hline Yunye 09-611 & 4 & MS \\
\hline Yunye 09-612 & 3 & MR \\
\hline Yunye 09-613 & 3 & MR \\
\hline Yunye 09-614 & 5 & $\mathrm{~S}$ \\
\hline Yunye 09-615 & 6 & $\mathrm{~S}$ \\
\hline Yunye 09-616 & 6 & $\mathrm{~S}$ \\
\hline Yunye 09-617 & 2 & $\mathrm{R}$ \\
\hline Yunye 09-618 & 1 & $\mathrm{HR}$ \\
\hline Yunye 09-619 & 8 & HS \\
\hline Yunye 09-620 & 5 & $\mathrm{~S}$ \\
\hline Yunye 09-621 & 8 & HS \\
\hline Yunye 09-622 & 1 & HR \\
\hline Yunye 09-623 & 5 & $\mathrm{~S}$ \\
\hline Yunye 09-624 & 8 & HS \\
\hline Yunye 09-625 & 6 & $\mathrm{~S}$ \\
\hline Yunye 09-626 & 2 & $\mathrm{R}$ \\
\hline Yunye 09-927 & 2 & $\mathrm{R}$ \\
\hline Yunye 09-628 & 7 & $\mathrm{~S}$ \\
\hline Yunye 09-629 & 2 & $\mathrm{R}$ \\
\hline Yunye 09-630 & 7 & $\mathrm{~S}$ \\
\hline Yunye 09-631 & 7 & $\mathrm{~S}$ \\
\hline Yunye 09-632 & 7 & $\mathrm{~S}$ \\
\hline Yunye 09-633 & 3 & MR \\
\hline Yunye 09-634 & 5 & $\mathrm{~S}$ \\
\hline Yunye 09-635 & 3 & MR \\
\hline Yunye 09-636 & 1 & HR \\
\hline Yunye 09-637 & 1 & HR \\
\hline Yunye 09-638 & 8 & HS \\
\hline Yunye 09-639 & 8 & HS \\
\hline Yunye 09-640 & 7 & $\mathrm{~S}$ \\
\hline Yunye 09-641 & 7 & $\mathrm{~S}$ \\
\hline Yunye 09-642 & 2 & $\mathrm{R}$ \\
\hline Yunye 09-643 & 8 & HS \\
\hline Yunye 09-644 & 2 & $\mathrm{R}$ \\
\hline Yunye 09-645 & 1 & HR \\
\hline Yunye 09-646 & 8 & HS \\
\hline Yunye 09-647 & 1 & HR \\
\hline Yunye 09-648 & 3 & MR \\
\hline Yunye 09-649 & 3 & MR \\
\hline Yunye $09-650$ & 6 & $\mathrm{~S}$ \\
\hline Yunye 09-651 & 7 & $\mathrm{~S}$ \\
\hline Yunye 09-652 & 1 & HR \\
\hline Yunye 09-653 & 6 & $\mathrm{~S}$ \\
\hline Yunye 09-654 & 7 & $\mathrm{~S}$ \\
\hline Yunye 09-655 & 6 & $\mathrm{~S}$ \\
\hline Yunye 09-656 & 6 & $\mathrm{~S}$ \\
\hline Yunye 09-657 & 7 & $\mathrm{~S}$ \\
\hline Yunye 09-658 & 7 & $S$ \\
\hline
\end{tabular}




\begin{tabular}{lcc}
\hline \hline Germplasm & Disease rating & Reaction $^{\text {a }}$ \\
\hline Yunye 09-659 & 6 & $\mathrm{~S}$ \\
Yunye 09-660 & 7 & $\mathrm{~S}$ \\
Yunye 09-661 & 6 & $\mathrm{~S}$ \\
Yunye 09-662 & 6 & $\mathrm{~S}$ \\
Ludashi (Female parent) & 2 & $\mathrm{R}$ \\
E.rockiiYunnan 95-19 (Male parent) & 1 & HR \\
Xuan 3 (susceptible cultivar) & 8 & HS \\
Guitang 89-5 (susceptible cultivar) & 8 & HS \\
M105 (susceptible cultivar) & 8 & HS \\
Guitang 84-332 (susceptible cultivar) & 9 & HS \\
P44 (susceptible cultivar) & 8 & HS \\
Mintang70-611 (resistant cultivar) & 1 & HR \\
\hline
\end{tabular}

aReaction: HR - highly resistant; MR - moderately resistant; R - resistant; MS - moderately susceptible; S - susceptible; HS - highly susceptible.

heritabilities were reported by Comstock et al. (1992c) and Hogarth et al. (1993). Daugrois et al. (1996) attributed rust resistance in progeny of the selfed cultivar ' $R$ 570' to a single major dominant gene. Although we did not study SCBR heritability, resistant introgression lines maybe important in China for breeding for resistance to $P$. melanocephala in commercial sugarcane cultivars. However, further studies are needed to determine the inheritance of resistance to $P$. melanocephala in China. It would be useful to 'tag' the resistant genotypes for resistance to $P$. melanocephala with molecular markers and use these markers to pyramid resistance genes into susceptible sugarcane cultivars.

\section{ACKNOWLEDGEMENTS}

We thank the Earmarked Fund for China Agriculture Research System (CARS-20-2-2) and the Earmarked Fund for Yunnan Province Agriculture Research System for project support.

\section{REFERENCES}

Berding N, Roach BT (1987) Germplasm collection, maintenance, and use. In: Heinz DJ (Ed.) Sugarcane improvement through breeding. Amsterdam The Netherlands. Elsevier. pp. 143-210.

Cai WY, Wu SJ (2006) Sugarcane for energy - a new highlight of sugarcane and sugar industry development. Sugarcane and Canesugar 3:22-25.

Comstock JC, Shine Jr. JM, Raid RN (1992a) Effect of rust on sugarcane growth and biomass. Plant Disease 76:175-177.

Comstock JC, Shine Jr. JM, Raid RN (1992b) Effect of early rust infection on subsequent sugarcane growth. Sugar Cane 4:7-9.

Comstock JC, Wu KK, Schnell RJ (1992c) Heritability of resistance to sugar cane rust. Sugar Cane 6:7-10.

Comstock JC, Raid RN (1994) Sugarcane common rust. In: Bhargava KS, Rao GP, Gillaspie Jr. AG, Upadhyaya PP, Bergamin Filho A, Agnihotri VP, Chen CT (Eds.) Current trends in sugarcane pathology. Delhi India. International Booksand Periodicals Supply
Service. pp. 1-10.

Daugrois JH, Grivet L, Roques D, Hoarau JY, Lombard H, Glaszmann JC, D'Hont A (1996). A putative major gene for rust resistance linked with a RFLP marker in sugar cane cultivar " $R$ 570". Theoretical and Applied Genetics 92:1059-1064.

Gonzalez RV, Manzano CA, Ordosgoitti FA, Salazar PY (1987) Genetica de la reaction de la caña de azúcar (Saccharum spp.) a Puccinia melanocephala, causante de la roya. Agronomia Tropical 37:99-116.

Hogarth DM, Ryan CC, Taylor PWJ (1993) Quantitative inheritance of rust resistance in sugar cane. Field Crops Research 34:187-193

Huang YK, Li WF (2002) Primary color map of main disease and insect pests of sugarcane. Kunming China. Yunnan Scientific and Technical Publishers.

Huang YK, Li WF (1998) Epidemic and control strategies of sugarcane rust disease in Yunnan. Plant Protection Technology and Extension 18:22-23.

Jiang DK (1985) Chemical control of sugarcane rust Puccinia melanocephala. Taiwan Sugar Research Institute 108:25-34.

Li WF, Cai Q, Huang YK, Fan YH, Ma L (2005) Identification of sugarcane wild germplasm resources resistant to Puccinia erianthi. Plant Protection 31:51-53.

Li WF, Cai Q, Huang YK, Fan YH, Ma L (2008) Identification of sugarcane cultivated origin species resistance to Puccinia erianthi. Journal of Yunnan Agricultural University 23:25-28.

Liu XL, Cai Q, Bi Y (2009) Genetic diversity analysis for germplasm of Erianthus rockii in China. Acta Agronomica Sinica $35: 262-269$.

Liu JL (1980) Sugarcane rust: Taxonomy, epidemiology, chemical control and relative resistance of sugarcane varieties in Puerto Rico. In: First Inter-American Sugar Cane Seminar: Cane disease. Miami FL, USA. Florida International University. pp. 54-58.

Ramdoyal K, Sullivan S, Lim Shin Chong LCY, Badaloo GH, Saumtally S, Domaingue R (2000) The genetics of rust resistance in sugar cane seedling populations. Theoretical and Applied Genetics 100:557-563.

Ryan CC, Egan BT (1989) Rust. In: Ricaud C, Egan BT, Gillaspie 
AG, Hughes CG (Eds.) Diseases of sugarcane. Amsterdam The Netherlands. Academic Press. pp. 189-210.

Tai PYP, Miller JD, Dean JL (1981) Inheritance of resistance to rust in sugar cane. Field Crops Research 4:261-268.
Taylor PWJ (1992) Evidence for the existence of a single race of common rust caused by Puccinia melanocephala, in Australian sugarcane cultivars. Australian Journal of Agricultural Research 48:443-450.

TPP-2012-0060 - Received 15 July 2012 - Accepted 13 November 2012

Section Editor: Rosana Rodrigues 